This is the peer reviewed version of the following article: "Gamez-Montero, PJ, Peña, $M$, Olmedo-Torre, N. Flipped learning and threshold concepts in the Turbomachinery section of Fluid Engineering course. Comput Appl Eng Educ. 2021; 29: 795-809" which has been published in final form at https://doi.org/10.1002/cae.22280. This article may be used for non-commercial purposes in accordance with Wiley Terms and Conditions for Self-Archiving." 


\title{
Flipped Learning and Threshold Concepts in the Turbomachinery Section of Fluid Engineering Course
}

\author{
Pedro Javier Gamez-Montero ${ }^{a}$, Marta Peña ${ }^{b}$ and Noelia Olmedo-Torre ${ }^{c}$ \\ aAFARG \& LABSON, Department of Fluid Mechanics, Universitat Politècnica de Catalunya, \\ Terrassa, Spain, pedro.javier.gamez@upc.edu; \\ ${ }^{b}$ Department of Mathematics, Universitat Politècnica de Catalunya, Barcelona, Spain, \\ marta.penya@upc.edu; \\ ${ }^{\mathrm{C} D}$ Department of Graphic and Design Engineering, Universitat Politècnica de Catalunya, \\ Barcelona, Spain, n.olmedo@upc.edu
}

\section{ABSTRACT}

This paper outlines a practical intervention aiming to collect the effects of introducing flexible learning in engineering higher education. The work discusses the implementation of the flipped classroom method and the threshold concepts in the Turbomachinery section of Fluid Engineering course in the third-year of Mechanical Engineering (Bachelor's degree) at the Universitat Politècnica de Catalunya. Fluid Engineering is traditionally one of the hardest courses involving a complex interaction between understanding concepts and using those concepts in the solution of cases, which also require the development of a set of skills. This case study is centred in two student cohorts and the research spans over two consecutive Fall semesters. The study is based on sound pedagogy to educational technologies in practice, frequent student-to-instructor interaction, academic results, statistical and survey analyses. A principal conclusion is that overall class performance is much higher than for the previous courses. The results indicate that learners gained understanding from semester to semester and no statistical significance was observed between group and exam format. Students were satisfied with the level of suitability and the degree of compliance of the new implementation and found it constructive in their learning process, an important educational benefit. This positive experience, in terms of benefit-cost and outcomes, encourages to extent the intervention without sacrificing any curriculum syllabus, but taking advantage and bringing the benefits of interactivity distance learning technologies and traditional face-to-face lectures. This scholarly research goals to contribute to this area, by abandoning traditional lecturing in favour of active learning.

\section{KEYWORDS}

Fluid engineering; turbomachinery; flipped classroom; threshold concepts; engineering education

\section{Introduction}

Engineering education is moving forward and engineering educators are and should be part of this transition. Improve student learning, prove it and demonstrate programme effectiveness are the basis undergoing in its transformation. Our societies are evolving in a way 
that technology is driving it and it is enhancing lectures with technology. Then, the instructors in engineering education cannot remain immune to this change. In such a sensitive matter, instructors and institutions of higher education may have to go hand in hand.

The traditional lecture, the face-to-face teaching and lecturing, has been the predominant mode of instruction since universities were founded over a millennium ago. The traditional lecturing approach is less efficient and gets worse learning outcomes than the active learning approach. This statement cannot be justified by an imperfect implantation of the traditional mode by an inexperienced lecturer, as it was shown by Deslauriers et al. [1] and Freeman et al. with a course performance of traditional lecturing versus active learning [2].

The active learning, in contrast to teacher-centred instruction, generates an environment in which inactivity and passivity are neither possible nor viable alternatives. It is not about throwing questions at the students so that the most uninhibited or quickest respond to them while most of their classmates take a break. The idea of an active learning is to achieve that all the students think about what are learning outside the formal class settings engaging them in the learning process.

\subsection{From traditional lecturing to flipped learning}

At the end of the 90s and beginning of the 21st century, several methodologies were developed to transmit and provide the information to be learned outside the class and to encourage their previous study by the students so that the class time could be devoted to active learning activities. Since then, there is increasing interest in research into class-based experiences that might enhance learning. In addition, there is no a unique learning style and each individual has his own.

The prototypical courses may be classified into four categories based on the proportion of the course delivery online [3]:

- traditional course: $0 \%$ online, delivering in writing or orally

- web facilitated course: $1-29 \%$ online, web-based technology to facilitate what is essentially a face-to-face course

- b-learning-blended/hybrid course: $30-79 \%$ online, blending online and face-to-face delivery

- e-learning-online course: $80-100 \%$ of the course content is delivered online.

It is not the purpose of this work to summarize all learning styles and learning methods, but several methods under the active learning approach are briefly named to entail active to flipped learning. Three approaches are centred and devoted to the 'student' (Peer Instruction, Team Based Learning and Just-in-Time Teaching), whilst the Japanese Lesson Study approach is centred and devoted to the 'instructor development'.

\subsection{Threshold concepts}

A threshold concept represents a milestone without which the learner cannot progress within a particular discipline. A threshold concept is more than 'I get it!' moment since it is a breakpoint that irreversibly transforms the learner. Once a threshold concept is achieved, the learner is taken to a new domain where a novel and previously inaccessible way of thinking about a matter lasts for a meaningful period of time. In comparison, a core concept is rooted in established knowledge [4] and a concept inventory is designed to determine the degree to which students understand the concepts of a subject and to identify the misconceptions [5]. 
Another collateral action of threshold concepts in engineering education is the identification of the troublesome to learn to think and understand like an engineer [6].

\subsection{Inverted teaching: the flipped classroom}

The genesis of the inverted teaching has its origin at the end of the previous century where the design of the new class model driven by cognitive approaches, it was also sought to retain some of the strengths of the traditional lecture approach. The advances in technology helped the conceptual transition from an instructor to a learner model at the beginning of the current century [7]. However, the breakpoint of the inverted teaching to the flipped classroom approach is the work of Bergmann and Sams [8]. Fruit of their friendship in 2004 and common educational concerns, these two high school chemistry teachers began video-taping their lectures in 2006 to help learners catch up when missing classes due to illness or sporting events. They posted the videos in an open educative resource and the miracle happened: the students watched the videos before class. Consequently, since it was not necessary to dedicate class time to long explanations, the students finished the problems in class in a short time (obviously, with some invaluable small help from the teachers). The students' grades improved significantly and teachers and students from all over the world began to send them emails thanking for the videos.

On the other hand, this breakthrough of the flipped classroom is not independent and isolated from initiatives such as the opened access to the OpenCourseWare of MIT in 2001, the Khan Academy in 2006 and the $e d X$ platform for education and learning founded by Harvard and MIT in 2012, among others, being just examples of this change of educational practice.

The flipped classroom state-of-the-art can be understood by the reviews and literature surveys carried out by researchers in the past five years. These inclusive surveys help to comprehend the current flipped classroom research and provide a starting point prior going into practice. Hence, the flipped classroom can be defined as an educational technique that consists of two parts: interactive group learning activities inside the classroom (in-class activities), and direct computer-based individual instruction outside the classroom (out-ofclass activities) [9]. Several common points can be extracted and collected as follows as a scoping view:

- There is a lack of consensus on what exactly the flipped classroom is [9]. There is no single model for the flipped classroom to date but core features of the flipped learning approach include: content in advance, educator awareness of students understanding and learning during class time [10].

- Video instruction in and of itself does not appear responsible for changes in learning performance, but may provide additional time for in-class activities that enhance learning performance due to active learning [11]. Then, direct computer-based individual instruction outside the classroom ought to be complemented with other assignments.

- Other learning activities common in the flipped classroom differ both in their effectiveness and in the conditions necessary for enhancing learning performance [11].

- In general, student perceptions are relatively consistent: opinions tended to be positive, but there are invariably a few students who strongly disliked the change [9]. The introduction of a flipped classroom approach required clear expectations to be given to students to reduce their frustrations regarding the time taken to do the preclass activities [10] [12]. 
- There is much indirect evidence emerging of improved academic performance and a scarcity of conclusive evidences [10]. In 2018, Akçayır and Akçayır in their review of advantages and challenges of the flipped classroom stated that more than half of the studies reported that using the flipped model improves the learning performance of students (such as satisfaction, engagement, and motivation). The flipped model enhanced student satisfaction up to $18 \%$ and their level of engagement up to $14 \%$ [13].

- The year distribution of the studies published in the SSCl-indexed journal articles that examined the flipped classroom showed that after more than a decade, such studies began to steadily increase after 2012 and $79 \%$ of all the flipped classroom studies were conducted between 2015 and 2016. The majority of the reviewed studies (80\%) were conducted at the higher education level [13].

After reviewing the literature of flipped learning and weighing its pros and cons, the authors of this presented study saw and believed in the potential of this approach to overcome and improve our teaching.

\subsection{Flipped classroom in STEM and Fluid Mechanics}

The flipped classroom, or inverted classroom, has been increasingly gaining ground in higher education but receiving less attention in engineering subjects [14]. Fortunately, this trend has been changing in recent years and, currently, limited research exists. In 2016, a special issue collected research papers to explore the effectiveness of the flipped classroom in Science, Technology, Engineering and Mathematics (STEM) courses using parameters such as student performance, course experience, institutionalizing of findings, and long-term retention [15]. In this matter, three universities worked collaboratively in promoting and implementing the flipped classroom pedagogy in the targeted STEM courses and analysing the impact of the curricular changes [16]. In another recent study, the active learning implementation in higher education pointed out five important characteristics preferred by the students: clarity, flexibility, opportunities for application, timely guidance and feedback, and cognitive engagement [17].

The experience of traditional teaching in core engineering subjects, such as Fluid Mechanics, showed that the students tended to under-perform and a poor overall performance [18]. Moreover, Fluid Mechanics is one of the more disliked courses in the engineering curriculum due to the difficulty of the material [19] with the common large-enrolment in Fluid Mechanics courses, as a supplementary complexity to add [20]. In fact, "Mechanics" and "Fluids" are familiar concepts for any newly enrolled engineering student. However, when combined into the term "Fluid Mechanics", students are initially thrust into an unfamiliar subject [21]. If the key concepts involving this unfamiliar subject are not effectively learned and the misconceptions are not corrected at an early stage, then students find it difficult to be successful in this subject [22]. Webster, Majerich and Madden implemented the flipped classroom for an undergraduate course in Fluid Mechanics and the effects in terms of a postconcept inventory were highly significant [23].

Subsequently, it was reasonable the increasing interest in research into class-based experiences in Fluid Mechanics that might enhance learning and engagement, such as the Blended Learning, Peer Instruction and the Flipped Classroom.

Despite several examples of flipped classroom model interventions be not up to expectations [24] [22] and a significant negative impact on homework performance [25], it should also be pointed out that there are other examples of successfully flipping a Fluid 
Mechanics course, the majority of which are very positive and which contribute to enhance outcomes [23] [26] [27].

Fluid Engineering is traditionally one of the hardest courses for any Mechanical Engineering student. It involves a complex interaction between understanding concepts and using those concepts in the solution of cases, which also require the development of a set of skills. As a subject, and in common with Fluid Mechanics, it also contains a range of key threshold concepts [22]. However, there is a limited amount of scholarly research on the implementation and effectiveness of the flipped learning in the field of Fluid Engineering.

The presented case study outlines a practical intervention in the third-year of Mechanical Engineering (Bachelor's degree), in the subject named "Fluid Engineering" at the school named School of Industrial, Aerospace and Audiovisual Engineering of Terrassa (ESEIAAT) of the Universitat Politècnica de Catalunya.

Students demonstrate in the different evaluation methods of the Turbomachinery section that they are vaguely acquiring the ability to apply the fundamentals to the course-learning outcome. So, it was believed that introducing a new methodology, an active learning methodology, in one of these sessions could improve learning and, above all, obtain a deeper, personalized and comprehensive view.

The study was carried during two consecutive Fall semesters with the aim of collecting the effects of introducing flipped learning in engineering higher education. This case study aims to contribute to this area, by abandoning traditional lecturing in favor of active learning.

Hence, the hypotheses to contrast and validate in this work are the effectiveness in the student performance of the flipped model and the level of readiness, adaptation, significance and satisfaction within this section. In addition, this proposal of intervention was inspected by the seven principles for good practice of Chickering and Gamson [28].

This paper will be useful for those researchers interested in applying new experiences in flipped classroom based on sound pedagogy, frequent student-to-instructor interaction, academic results and survey analysis bringing the benefits of interactivity distance learning technologies.

\subsection{Diagnosed symptoms of the course}

The course of this first section of the subject (the object of this intervention, as described in the next Section), in the context of its timing in the schedule provided in the course syllabus, ECTS credits and the knowledge to acquire, exhibited warning symptoms that advised of a need to introduce a new methodology, an active learning methodology.

Regarding to the previous format of this first section of the subject, traditional lecturing, the symptoms are detected when during the session it is perceived that a part of the audience can lose interest and disconnect from it. The course evaluations and surveys indicated some students felt that lectures were primarily covering material by using the instructors' slides on the overhead projector and blackboard contents, and they preferred to be able to work on problems during the class period instead [25].

Regarding to student body, there is a wide diversity (different age, background levels, students returning to school after a long break period, part and full-time workers, etc.) making the teaching of the class very demanding. In addition, students' resolution and doubts rose 
during the problem-solving sessions confirmed this miscellany. Likewise, few students typically visited the instructor during his office hours.

\section{Methods}

All students have to enrol for the subject, since it is not an elective subject in the curriculum, and it takes 6 ECTS credits. The course of this subject is exclusively programmed in the Fall semester. The subject is divided into two immiscible sections based on the working fluid: first section, water, and second section, oil. Each section has its own instructor and they act individually and independently. The course typically has 75-100 students and is taught once a week for two hours of lecture and one hour of problem-based session. These formats do limit frequent student-to-instructor interaction and rather focuses on the delivery of content to a large number of students.

The intervention in this study only involves the first section, in which the working fluid is water. Hence, the first section is programmed in the first two-month period of the Fall semester and encompasses 6 sessions in total. The course covers Fluid Mechanics of Turbomachinery describing machines that transfer energy between a rotor and a fluid (water), and other material such as velocity triangle/diagram, Euler's equation, pump head and efficiency, dimensional analysis and similitude, dimensionless numbers and coefficients, and specific speed. In addition, the section works on applications with Turbomachinery involving performance curve centrifugal pump, pump system operating point and control valves. Control valves main contents are classification, capacity, selecting, $K v$ and fi definition, characteristics and authority distortion.

Previously, in the traditional course format of lecture, the course meets for $50+50$ minutes of class time each Friday evening. Students listen to the traditional face-to-face lecture, blackboard contents and the instructors' slides on the overhead projector. Even with significant effort to encourage participation and discussion, students mostly act passively. Attendance is neither required nor recorded. There is no possibility to teach in parallel the Turbomachinery section, since there is just one group of typically $75-100$ students and a single instructor with no assistants.

Not the whole course was taught using flipped classroom technique. During each semester only one session was flipped and two threshold concepts covered by the lecture. Once decided to flip one session, students were informed in detail one month in advance, fully explained and repeated in all lectures.

\subsection{Model implementation and description of the intervention}

The intervention in this study is concentrated in the last session in the Turbomachinery section of Fluid Engineering. Then, the identification of the threshold concepts and the flipped classroom was performed to the Control Valves lecture, the last lecture of the syllabus of this section. Figure 1 shows the mind map of the Turbomachinery section and the lecture of intervention.

The intervention is planned to put into practice in 15 days with a total scheduled timing of activities, in- and out-of-class, of 240 minutes (4 hours). The planning of the activities is presented in Figure 2. This planning was scheduled at the beginning of the course, and it was explained and posted to students one month in advance. 


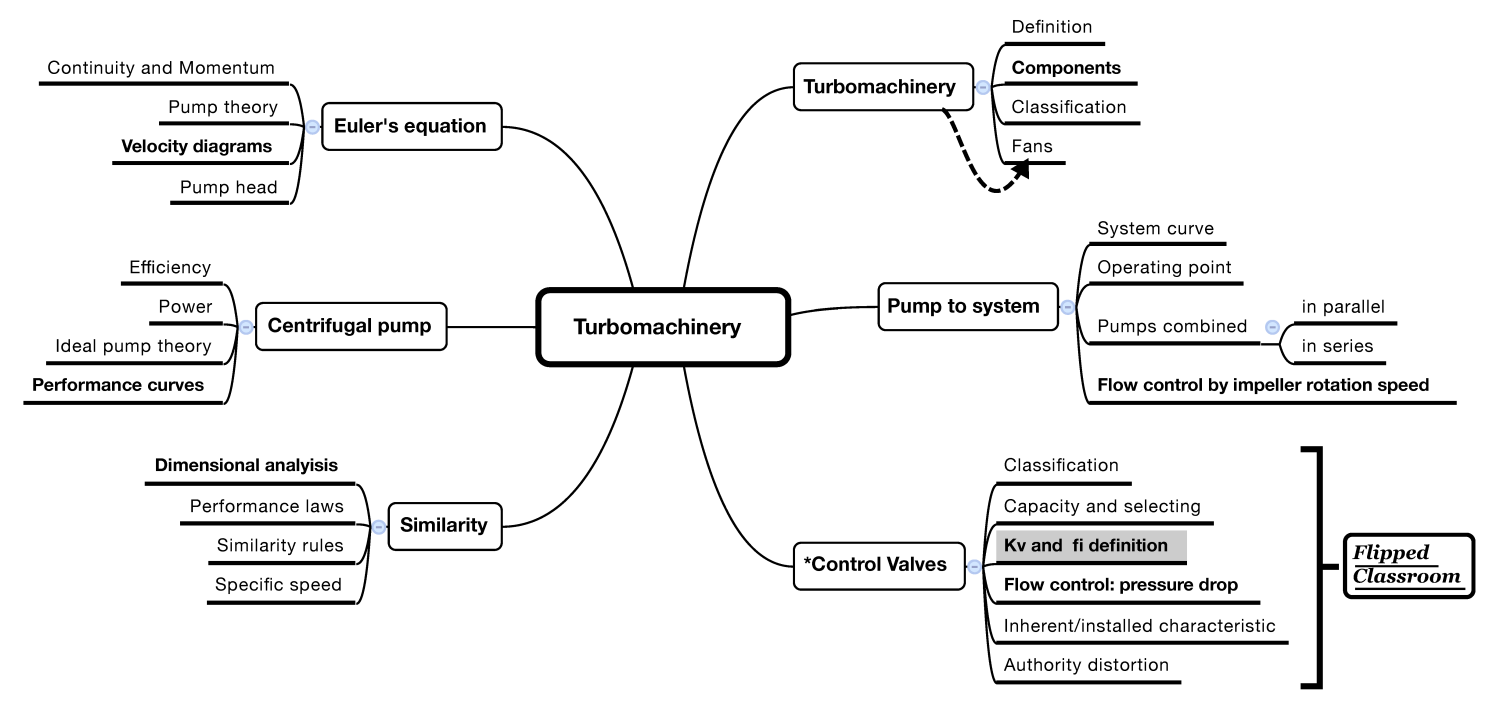

Figure 1. Mind map of the Turbomachinery section. The threshold concepts highlighted in grey in the flipped classroom lecture of Control Valves.

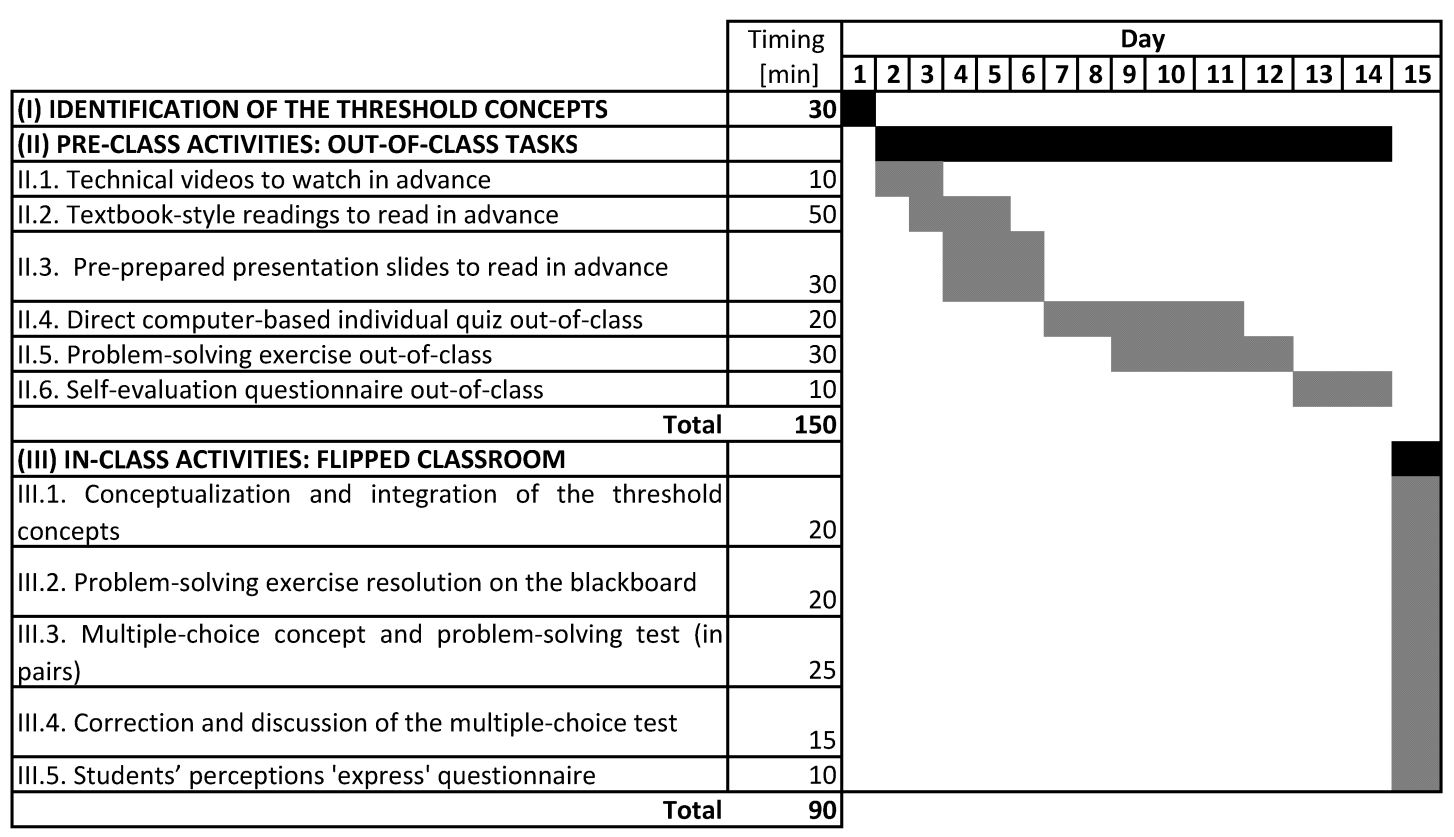

Figure 2. Planning scheduling all in- and out-of-class activities of the intervention.

(I) Identification of the threshold concepts by the instructor

The instructor explored the process to push out the threshold concepts in the Control Valves lecture. The labels of these two threshold concepts (the signifier) are well-known accepted terminology, whereas the concept (the signified) is the Achilles' heel in order to produce disruptive learning [29]. The instructor identifies, conceptualizes and discusses them to open the gate to a technical understanding, like a fluid engineering engineer to solve realworld problems [30]. Figure 1 shows the two threshold concepts. 
In-class scheduled timing: 30 minutes programmed at the end of previous lecture to the Control Valves flipped lecture.

(II) Pre-class activities by the students: out-of-class tasks

The pre-class activities are out-of-class tasks to be carried out by the students and previously the flipped classroom intervention.

Total out-of-class scheduled timing: 150 minutes.

\section{II.1. Technical videos to watch in advance selected by the instructor}

Bloom's Taxonomy [31]: Remember. List types, primary specific details and elements in control valves.

Activity specification: Students watched very short and explicit, online videos before class. The instructor selected the videos from a technical approach; although these videos were not recorded from his own lectures. Instead, the videos followed the contents on 3D animations of different types of control valves. Links to the online video lectures that the students were expected to watch in advance of that session were available on servers at Universitat Politècnica de Catalunya, with good technical support. This teaching support platform is named ATENEA.

Scheduled timing: 10 minutes

\subsection{Textbook-style readings to read in advance selected by the instructor}

Bloom's Taxonomy: Remember. Recognize the interrelationships among the basic elements within the larger structure of a Control Valve that enable them to function together and recall terminology.

Activity specification: The format and methodology employed in the out-of-class content delivery in the flipped classroom model is more than video contents and this study includes, as a direct computer-based individual instruction, reading assessments as an out-of-class activity. Assigning reading outside of class is not just for afterwards having discussions in class, which could be tempting to students to not complete it. In the Turbomachinery section is important this reading activities, and then, to ensure the students complete the assignment, direct computer-based individual test out-of-class is planned. The readings assessments are open access to students and were stored in the teaching support platform ATENEA, on servers at Universitat Politècnica de Catalunya.

Scheduled timing: 50 minutes

\subsection{Pre-prepared presentation slides to read in advance selected by the instructor}

Bloom's Taxonomy: Remember. Identify self-knowledge and retain the main concepts summarized in the instructors' material.

Activity specification: The own prepared slides of the instructor were stored in the teaching support platform ATENEA as pre-reading activity. Since the previous five sessions were taught by using the own prepared slides of the instructor, it was appropriate to deliver a transition between traditional lectures and the flipped classroom.

Scheduled timing: 30 minutes 


\section{II.4. Direct computer-based individual quiz out-of-class}

Bloom's Taxonomy: Understand. Explain and interpret the main concepts.

Activity specification: Online multiple-choice concept quiz that is answered individually. The multiple-choice concept quiz is delivered via the ATENEA platform and available for 72 hours, opening 120 hours and closing 48 hours the starting of the flipped classroom. In this period, students can attempt the quiz once in the 20 minutes scheduled timing and no specific marks are assigned but if they did respond, the student was awarded in associated final examination. Results are not visible to students until they have attempted and finished the quiz, displaying the correct answers and marking the errors as soon as the quiz is completed. Figure 3 depicts a screenshot showing an example question asked in the computer-based individual quiz activity.

Scheduled timing: 20 minutes

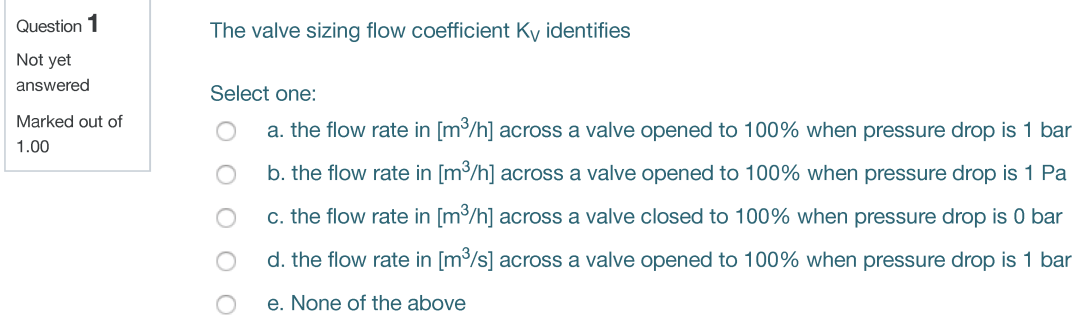

Figure 3. Screenshot showing a question asked in the quiz (Note: translation from originally Spanish into English).

\subsection{Problem-solving exercise out-of-class}

Bloom's Taxonomy: Understand. Demonstrate understanding of the main concepts.

Activity specification: The problem statement is set out plain and feasible to promote selfknowledge. Students scanned and provided the handwritten resolution in the corresponding folder in PDF file format in ATENEA. After 72 hours, the instructor's handwritten solution to the out-of-class problem was posted in the corresponding folder in PDF file format in ATENEA. A mark was allocated for bringing this task to completion in this 72 hours' period.

Scheduled timing: 30 minutes

\subsection{Self-evaluation questionnaire out-of-class}

Bloom's Taxonomy: Understand. Outline misperceptions and interpret misconceptions.

Activity specification: The student compared and contrasted to self-evaluation the own handwritten resolution to the instructor's handwritten solution. Response to this questionnaire was voluntary, no mark was allocated for the completion of this task and a brief feedback was provided in base of the punctuation of their answers. The feedback was automated and, therefore, immediate.

The questions to self-evaluation of the questionnaire:

- Hypotheses: All hypotheses are included.

- Drawings: The sketches/schemes are included in detail setting up the problem. 
- Explanation: The explanation of the resolution is comparable to the instructor's solution.

- Resolution: The physical concepts are presented and comparable to the instructor's solution.

- Resolution: The numerical results are correct.

- Difficulty: The problem statement is workable with the planning and material provided by the instructor.

- Knowledge: The planning and material provided by the instructor enhance and promote the learning of this activity.

- Satisfaction: My learning is satisfactory.

The self-score of these questions were:

- 4 (maximum); 3; 2; 1 (minimum).

The feedback was automated and, therefore, immediate:

- Scoring 100\%: Perfect! You have completed the task with the maximum learning outcomes. Congratulation, go on!

- Scoring up to 60\%: You have not completed this task with all the indispensable guarantees and learning outcomes. I recommend you to carry it out again and work the concepts thoroughly.

- Scoring up to 45\%: You have not completed the minimum learning outcomes. I recommend you contact me by email to set up an appointment during my office hours.

Scheduled timing: 10 minutes

\subsection{Revision of programmed pre-class activities by the instructor}

From the beginning of this intervention, the instructor communicated to the students the revision of programmed pre-class activities. These out-of-class task were manually-graded by the instructor to give 'just-in-time feedback' in the in-class activities of the flipped classroom session pointing out misconceptions and possible alternative resolutions of the problemsolving exercise. By answering these activities based on prior knowledge and understanding, it is anticipated that associating the concepts with ideas already understood. This activity is not shown in Figure 2.

(III) In-class activities by the students and instructor: flipped classroom

The flipped classroom intervention was outlined to devote class time to a variety of learning activities.

Total in-class scheduled timing: 90 minutes.

\section{III.1. Conceptualization and integration of the threshold concepts by the instructor}

Bloom's Taxonomy: Understand. Awareness of one's own cognition of the threshold concept and knowledge its accomplishment for a meaningful period of time.

Activity specification: Clarify any misunderstandings students may have helping students overcome threshold concepts.

Scheduled timing: 20 minutes 


\section{III.2. Problem-solving exercise resolution on the blackboard}

Bloom's Taxonomy: Understand. Clarify assembly instructions of subject-specific techniques and methods and knowledge of criteria for determining when to use appropriate procedures.

Activity specification: Students were provided with a brief discussion on the problemsolving exercise based on the revision performed by the instructor clarifying any misunderstandings they may have. To consolidate learning, another brief example of problemsolving exercise was exposed and discussed on the blackboard by the instructor.

Scheduled timing: 20 minutes

\section{III.3. Concept and problem-solving multiple-choice test (in pairs)}

Bloom's Taxonomy: Apply. Choose the correct answer and respond to frequently asked concepts, use problem-solving techniques, utilize the formulation and solve related problem statements.

Activity specification: The design goal was to have the students (in pairs) spend all this specific time in class hands-on activities engaged in pairs in deliberate practice at "thinking engineeringlly". This test involves an element of camaraderie with a previously chosen classmate. The test is the same for all students and is answered in pairs in the class time and consists of eight multiple-choice questions with five choices that address both concepts and problems. The scheduled timing allowed to take the test is not sufficient for them to be answered individually, so cooperation with the partner is required.

Scheduled timing: 25 minutes

\section{II.4. Correction and discussion of the multiple-choice test}

Bloom's Taxonomy: Identify. Examine and break the resolution into parts by identifying the misconstructions, miscalculations, mistakes and misconceptions.

Activity specification: The instructor provided critical "just-in-time tutoring" during the inclass just after students finished the multiple-choice test [23]. The correction showed the location of the answer of each question in the pre-class material (readings, slides and quiz) via overhead projector in conjunction with blackboard problem-solving resolution.

Scheduled timing: 15 minutes

\section{III.5. Students' perceptions 'express' questionnaire}

Activity specification: The instructor delivered a questionnaire document to be filled by hand to gain immediate, 'express', student feedback regarding format, design, difficulty, satisfaction, etc., of the flipped classroom intervention. The instructor ad-hoc elaborated this questionnaire to ask students for their response regarding the flipped classroom design. The questionnaire was completed as anonymous responses. Post-course surveys are carried out by the university.

Scheduled timing: 10 minutes

The 'express' questionnaire comprised six questions to rank certain aspects on a scale of $0-$ 10 (maximum) and it is depicted in Figure 4. The questionnaire has been translated to English to be presented here, whilst students completed it reading the questions in Spanish. 
Students' perceptions 'express' questionnaire: “Control Valve Flipped Classroom”

The questionnaire is completed as anonymous responses.

Your opinions are very valuable and will help to improve the intervention in future editions.

\begin{tabular}{|c|c|c|}
\hline Did you hear about the 'Flipped Classroom' before the instructor's proposal? & Yes & No \\
\hline $\begin{array}{l}\text { 1. Rank on a scale of } 0-10(0: \min -10: \max ) \text { how much you understood (level of } \\
\text { knowledge) of the purpose of this intervention (approach) and the means to perform } \\
\text { it (video, readings, slides, material, documents, etc.) from the introduction/presentation } \\
\text { of the Flipped Classroom intervention. }\end{array}$ & & \\
\hline $\begin{array}{l}\text { 2. Rank on a scale of } 0-10(0: \min -10: \max ) \text { how much you understood (level of } \\
\text { knowledge) of how to complete (what have to be done and how, where and when to } \\
\text { deliver it) and time on tasks (allocated to realistic amounts of time and time } \\
\text { expectations) from the explanation of the Flipped Classroom intervention. }\end{array}$ & & \\
\hline $\begin{array}{l}\text { 3. Rank on a scale of } 0-10(0: \min -10: \max ) \text { the level of suitability (learning outcomes) } \\
\text { and the degree of compliance for your understanding of the activities of the Flipped } \\
\text { Classroom intervention. }\end{array}$ & & \\
\hline $\begin{array}{l}\text { 4. Rank on a scale of } 0-10(0: \min -10: \max ) \text { how challenging (level of difficulty under } \\
\text { feasible perception) of the pre-class and in-class activates of the Flipped Classroom } \\
\text { intervention. }\end{array}$ & & \\
\hline $\begin{array}{l}\text { 5. Rank on a scale of } 0-10(0: \min -10: \max ) \text { the degree of quality of materials and } \\
\text { homogeneity of guidelines to accomplish the pre-class activities of the Flipped } \\
\text { Classroom intervention. }\end{array}$ & & \\
\hline $\begin{array}{l}\text { 6. Rank on a scale of } 0-10(0: \min -10: \max ) \text { the level of satisfaction of your experience } \\
\text { in participating of the Flipped Classroom. }\end{array}$ & & \\
\hline
\end{tabular}

Are there any other comments that you would like to add? Please, briefly indicate any aspect that it could have been carried out more effectively and any suggestion in this regard.

Figure 4. Students' perceptions 'express' questionnaire (Note: translation from originally Spanish into English).

\section{Results and Discussion}

The data are representing two student cohorts, two different groups of students in 2018 and 2019 Fall semesters, from now on shorten as 1Q-1819 and 1Q-1920. The enrolment figures in each group were 81 students (1Q-1819) and 91 students (1Q-1920), respectively.

The student population in the 1Q-1819 group included $16 \%$ female students and in the $1 Q-$ 1920 group included $11 \%$ female students. Nevertheless, it was decided do not specifically ask in any survey or questionnaire. In addition, it was decided do not perform any approach regarding to gender results.

\subsection{Assessments: format and type}

The intervention performance is evaluated by means of the scores/grades in test, exercise and final examination described as follows:

QU_VA: this acronym stands for the score obtained in the "III.3. Concept and problemsolving multiple-choice test (in pairs)" as the in-class activity by the students in the flipped classroom session: the Control Valves lecture. 
EX_VA: this acronym stands for the score obtained in the problem-solving exercise in the Turbomachinery section final examination. The weight of this exercise in the final examination is $25 \%$ and it is based on the "II.5. Problem-solving exercise out-of-class" and "III.2. Problemsolving exercise resolution on the blackboard", both strictly related to the Control Valves lecture.

EX_MH: this acronym stands for the score obtained in the Turbomachinery section final examination, and consequently, the maximum total score is $100 \%$.

The score range in all formats and types (test, exercise and final examination) is from 0 (minimum score) to 10 (maximum score). To keep the data comparable, test, exercise and examination administered were identical and with a similar level for both groups.

\subsection{Participants and students' performance}

The number of students participating in the test of each group was 74 (91\%, QU_VA_1Q$1819)$ and 86 (94\%, QU_VA_1Q-1920), respectively. The number of students participating in the final examination of each group was 79 (98\%, EX_MH_1Q-1819) and 88 (97\%, EX_MH_1Q1920), respectively.

Despite of the fact that the QU_VA was a multiple-choice test (in pairs) and the EX_VA was an exercise (on your own) in the final examination, it was believed that a statistically significant comparison would be enriching owing to both of them are based on problem-solving. Table 1 shows the results of two-sample t-tests to observe if there was a statistical significance in the student performance between groups and type-format for the Control Valves section.

Table 1. Comparison strictly related to the Control Valves section of test, in-class activity flipped classroom session, and exercise, problem in the final examination. Reported values are [participation] mean (standard deviation).

\begin{tabular}{lccc}
\hline & 1Q-1819 group & 1Q-1920 group & $\begin{array}{c}p \text {-value } \\
(10-1819 \text { vs. 1Q-1920) }\end{array}$ \\
\hline QU_VA test & {$[74] 8.4(1.71)$} & {$[86] 9.9(0.36)$} & $<0.001^{*}$ \\
EX_VA exercise & {$[79] 6.5(3.82)$} & {$[88] 7.6(2.9)$} & $0.027^{*}$ \\
$p$-value & $<0.001^{*}$ & $<0.001^{*}$ & \\
(QU_VA vs. EX_VA) & & \\
$\begin{array}{l}\text { *indicates significant result (p-value <0.05), statistically significant comparison with } \alpha=0.05 \text { (equal variances were } \\
\text { not assumed for these analyses) }\end{array}$
\end{tabular}

Overall, no statistical significance was observed neither between groups nor by type-format (Table 1). The mean score on the QU_VA test was significantly higher in the second group, 1Q1920, the same as the EX_VA exercise. This result indicated that students in both test and exercise gained understanding of Control Valve concepts from semester to semester and interpreted as a favorable tendency. With regard to QU_VA and EX_VA, for both groups, the values of standard deviation disclosed the type of assessment and scoring between multiplechoice test and problem-solving exercise. It is significant the mean score and standard deviation in the QU_VA test of the second group, showing a great performance of the students. 'In pairs' and 'on your own' resolutions in test and exercise, respectively, are also highlighted.

The mean score on the final examination was slightly higher among the students in the second group (EX_MH_1Q1920: [88] 5.9 (1.91); [participation] mean (standard deviation)) 
compared to the students in the first group (EX_MH_1Q1819: [79] 5.3(2.21)), although this result was only marginally significant $(p$-value $=0.065)$. These results are aligned those reported by Webster, Majerich and Madden [23].

Further, a correlation approach was conducted within the scores of the exercise of control Valves in the final examination EX_VA and the scores of the final examination EX_MH for both groups. The correlation approach was used to control for relation between the exercises exclusively based on Control Valves as independent variable of the final examination performance. The Pearson Correlation performed showed that EX_VA exercise significantly correlates with the overall final examination score, as expected: EX_MH, r(1Q-1819) $=0.723 ; p$ $<0.001$ and $r(1 Q-1920)=0.639 ; p<0.001$.

\subsection{Students' perceptions 'express' questionnaire}

The students' perceptions 'express' questionnaire was employed to measure the flipped classroom intervention, which consisted of six questions to rank certain aspects on a scale of 0-10 (maximum, see Figure 4). In order to determine if the scale is reliable in a multiple Likert type questionnaire, Cronbach's alpha calculation is used to measure the internal consistency. The scale had a high level of internal consistency, as determined by a Cronbach's alpha of 0.76 (1Q-1819) and 0.88 (1Q-1920). Higher values of Cronbach's alpha are better since the recommended values for a good level of internal consistency are 0.7 or higher. Results appear in Table 2.

Table 2. Flipped classroom 'express' questionnaire responses from learners. Reported values are mean (standard deviation).

\begin{tabular}{|c|c|c|}
\hline Fall semester & 1Q1819 & 1Q1920 \\
\hline Number of responses & $\begin{array}{c}74 \\
(91 \%)\end{array}$ & $\begin{array}{c}85 \\
(94 \%)\end{array}$ \\
\hline $\begin{array}{l}\text { Did you hear about the 'Flipped Classroom' before the instructor's } \\
\text { proposal? }\end{array}$ & $\begin{array}{c}\text { Yes } \\
(14 \%)\end{array}$ & $\begin{array}{l}\text { Yes } \\
(13 \%)\end{array}$ \\
\hline $\begin{array}{l}\text { 1. Rank on a scale of } 0-10 \text { ( } 0 \text { : } \min -10: \text { max) how much you understood } \\
\text { (level of knowledge) of the purpose of this intervention (approach) and the } \\
\text { means to perform it (video, readings, slides, material, documents, etc.) from } \\
\text { the introduction/presentation of the Flipped Classroom intervention. }\end{array}$ & $\begin{array}{c}8.12 \\
(1.44)\end{array}$ & $\begin{array}{c}7.95 \\
(1.23)\end{array}$ \\
\hline $\begin{array}{l}\text { 2. Rank on a scale of } 0-10 \text { (0: } \min -10: \max \text { ) how much you understood } \\
\text { (level of knowledge) of how to complete (what have to be done and how, } \\
\text { where and when to deliver it) and time on tasks (allocated to realistic } \\
\text { amounts of time and time expectations) from the explanation of the Flipped } \\
\text { Classroom intervention. }\end{array}$ & $\begin{array}{c}8.41 \\
(1.42)\end{array}$ & $\begin{array}{c}8.27 \\
(1.47)\end{array}$ \\
\hline $\begin{array}{l}\text { 3. Rank on a scale of } 0-10(0: \min -10: \max ) \text { the level of suitability } \\
\text { (learning outcomes) and the degree of compliance for your understanding of } \\
\text { the activities of the Flipped Classroom intervention. }\end{array}$ & $\begin{array}{c}8.46 \\
(1.20)\end{array}$ & $\begin{array}{c}7.67 \\
(1.44)\end{array}$ \\
\hline $\begin{array}{l}\text { 4. Rank on a scale of } 0-10 \text { ( } 0 \text { : } \min -10 \text { : } \max \text { ) how challenging (level of } \\
\text { difficulty under feasible perception) of the pre-class and in-class activates of } \\
\text { the Flipped Classroom intervention. }\end{array}$ & $\begin{array}{c}8.39 \\
(1.42)\end{array}$ & $\begin{array}{c}7.66 \\
(1.39)\end{array}$ \\
\hline $\begin{array}{l}\text { 5. Rank on a scale of } 0-10(0: \min -10: \max ) \text { the degree of quality of } \\
\text { materials and homogeneity of guidelines to accomplish the pre-class } \\
\text { activities of the Flipped Classroom intervention. }\end{array}$ & $\begin{array}{c}8.81 \\
(1.24)\end{array}$ & $\begin{array}{c}8.38 \\
(1.17)\end{array}$ \\
\hline $\begin{array}{l}\text { 6. Rank on a scale of } 0-10 \text { ( } 0: \text { min }-10: \max \text { ) the level of satisfaction of } \\
\text { your experience in participating of the Flipped Classroom. }\end{array}$ & $\begin{array}{c}8.64 \\
(1.36)\end{array}$ & $\begin{array}{c}7.49 \\
(1.29)\end{array}$ \\
\hline
\end{tabular}


The number of responses in each group was $74(91 \%, 1 Q-1819)$ and $86(94 \%, 1 Q-1920)$ showing representativeness. The number of students being knowledgeable of the flipped classroom before the instructors' proposal is surprisingly low in both groups, 14\% (1Q-1819) and $13 \%(10-1920)$. The number of students who failed the subject from the previous Fall semester 1Q-1819, grade repeaters, was 11 , just a $12 \%$ of the enrolled students and almost the same number of the students being knowledgeable of the flipped classroom. The second group does not show a knowledge-transfer from the previous group. Consequently, the good results of the Fall semester 1Q-1920 cannot be directly endorsed to this fact.

The student perspective from Table 2 is that the evaluation of the 1Q-1920 group is slightly lower than the 1Q-1819 group in all six questions. This tendency could be driven, in part, by the differences in the attendance and size of the class for the two groups. Frustrating as this research finding could be, the results may not hold true for all the intervention.

Another interesting feature noted in Table 2 is the visible highest valuation to the degree of quality of materials and homogeneity of guidelines to accomplish the pre-class activities of the Flipped Classroom intervention for both groups. In addition, it could be conjectured that the format and methodology employed in the out-of-class content delivery in the flipped classroom model have a limited impact in the overall student learning, as it was demonstrated in the work of Jensen et al. [32]. The investigation was run with three instructors collecting data from 657 undergraduate students at two institutions (private and public) using three different methods of out-of-class content delivery: interactive tutorials (posed questions and solicited feedback from students); video lectures (the same material but presented by one of the instructors in a video format with no interaction by students); and textbook-style readings (the same material but written in the form of a textbook passage with no interaction by students). However, the most important finding was that, despite the inequality in preparedness to effectively learn from out-of-class activities, both institutions demonstrated equivalent learning gains after by the final assessment which reinforces the effectiveness of the student-centred approach of the flipped classroom model.

A surprising outcome was that the video lectures appeared to offer a small advantage to overall student learning. Nevertheless, the instructor could improve the specific format of the video as it was pointed out in the student comments and feedback as shown in the next section.

\subsection{Student comments and feedback}

Overall, student feedback was very positive both regarding the Turbomachinery section as well as the flipped classroom session. Several students made similar global comments about the flipped format as (translation from originally Spanish into English):

"The subject is complex and learning is more difficult, so this new tool is very good and innovative (at the same time different and enjoyable); it is another format designed for topics with a certain level of complexity."

"A good approach to motivate the students to gain knowledge without in-class presence and in a hands-on methodology."

Also, a student made an interesting feedback to take into consideration before planning the next Fall semester: 
"The videos would be more useful with some kind of explanation about each valve; for example, with subtitles."

\subsection{Instructor and course evaluation: SEEQ questionnaire}

The Student Evaluation of Educational Quality (SEEQ) questionnaire is one of the most thoroughly developed and widely used student feedback questionnaire [33]. The SEEQ is an instrument which allows to analyze the efficiency of teaching using nine dimensions or items to produce a single score as an overall indicator of educational quality: Learning, Enthusiasm, Organization, Group interaction, Individual rapport, Breadth, Examinations, Assignments and Overall. Each dimension has the answers in the format of a typical five-level Likert scale: strongly disagree (1), disagree (2), neutral (3), agree (4) and strongly agree (5).

The SEEQ questionnaire has been used in the Turbomachinery section since the beginning of teaching of this course, seven years ago. A data set of seven semesters in a row is reported in Table 3.

Table 3. SEEQ questionnaire results. Reported values are 'Participation', number of questionnaires (\% enrolment figure) and SEEQ items, mean (standard deviation). $\bar{X}$ is the overall average of these seven semesters; for example, 13/14 stands for 2013 Fall semester.

\begin{tabular}{|c|c|c|c|c|c|c|c|c|}
\hline $\begin{array}{l}\text { Fall semester 1Q- } \\
\text { Variable }\end{array}$ & $13 / 14$ & $14 / 15$ & $15 / 16$ & $16 / 17$ & $17 / 18$ & $18 / 19$ & $19 / 20$ & $\bar{X}$ \\
\hline \multirow[t]{2}{*}{ Participation } & 73 & 82 & 86 & 77 & 101 & 81 & 91 & 84 \\
\hline & $84 \%$ & $77 \%$ & $99 \%$ & $99 \%$ & $72 \%$ & $94 \%$ & $76 \%$ & $86 \%$ \\
\hline \multirow[t]{2}{*}{ Learning } & 3.84 & 4.04 & 3.99 & 3.91 & 4.22 & 3.92 & 3.97 & 3.98 \\
\hline & $(0.73)$ & $(0.77)$ & $(0.73)$ & $(0.72)$ & $(0.67)$ & $(0.84)$ & $(0.72)$ & \\
\hline \multirow[t]{2}{*}{ Enthusiasm } & 3.92 & 4.26 & 4.34 & 4.34 & 4.58 & 4.39 & 4.38 & 4.32 \\
\hline & $(0.87)$ & $(0.75)$ & $(0.77)$ & $(0.66)$ & $(0.56)$ & $(0.78)$ & $(0.79)$ & \\
\hline \multirow[t]{2}{*}{ Organization } & 3.89 & 4.09 & 4.13 & 4.07 & 4.28 & 4.24 & 4.22 & 4.13 \\
\hline & $(0.81)$ & $(0.84)$ & $(0.80)$ & $(0.82)$ & $(0.69)$ & (0.79) & $(0.83)$ & \\
\hline \multirow[t]{2}{*}{ Group interaction } & 3.60 & 3.82 & 3.95 & 3.68 & 4.04 & 3.72 & 3.61 & 3.77 \\
\hline & $(0.84)$ & $(0.85)$ & $(0.82)$ & $(0.87)$ & $(0.83)$ & $(0.94)$ & $(0.98)$ & \\
\hline \multirow[t]{2}{*}{ Individual rapport } & 3.97 & 4.36 & 4.40 & 4.32 & 4.46 & 4.13 & 4.24 & 4.27 \\
\hline & $(0.88)$ & $(0.74)$ & $(0.67)$ & $(0.78)$ & $(0.67)$ & $(0.84)$ & $(0.79)$ & \\
\hline \multirow[t]{2}{*}{ Breadth } & 3.69 & 3.94 & 3.88 & 3.88 & 4.05 & 3.89 & 3.94 & 3.90 \\
\hline & $(0.73)$ & $(0.79)$ & $(0.81)$ & $(0.83)$ & $(0.70)$ & $(0.81)$ & $(0.82)$ & \\
\hline \multirow[t]{2}{*}{ Examinations } & 3.67 & 3.95 & 3.74 & 3.81 & 3.92 & 3.86 & 3.76 & 3.82 \\
\hline & $(0.76)$ & $(0.88)$ & $(0.88)$ & $(0.84)$ & $(0.77)$ & $(0.97)$ & $(0.85)$ & \\
\hline \multirow[t]{2}{*}{ Assignments } & 3.50 & 3.80 & 3.68 & 3.62 & 3.68 & 3.89 & 3.85 & 3.72 \\
\hline & $(0.79)$ & $(0.91)$ & $(0.74)$ & $(0.91)$ & $(0.79)$ & $(0.94)$ & $(0.77)$ & \\
\hline \multirow[t]{2}{*}{ Overall } & 3.14 & 3.19 & 3.27 & 3.34 & 3.18 & 3.35 & 3.57 & 3.29 \\
\hline & $(0.79)$ & $(0.92)$ & $(0.86)$ & $(0.85)$ & $(0.75)$ & $(0.97)$ & $(0.96)$ & \\
\hline
\end{tabular}


In general, the SEEQ outcomes are really positive, especially in 'Enthusiasm' and 'Individual rapport'. It can be seen from Table 3 that item scores gradually grow from the first Fall semester 13/14 up to the last two Fall semesters 18/19 and 19/20, in which the Flipped Classroom intervention occurred. Unfortunately, within the extent of the current data set of seven semesters, it is quite difficult to find any specific reason to explain the success or failure of Flipped Classroom approach. A reason could be found in the duration of the treatment, which was very specific (one lecture over five), and topics on the previous lectures of the flipped topics were still taught with traditional methods.

\section{Conclusions and future work}

This paper presents a post hoc analysis of a student-centred approach based on Flipped Classroom intervention linked to Threshold Concepts in the Turbomachinery section of a Fluid Engineering course in the Universitat Politècnica de Catalunya. This case study is centred in two student cohorts and the research spans over two consecutive Fall semesters, 2018 and 2019. The flipped model was applied to the Control Valves lecture, the last lecture of the syllabus of this section, which before this intervention was regarded as high difficult contents.

Overall class performance in the final examination at the end of the Turbomachinery section is much higher than for the previous Fall semester. The same tendency is observed with the Flipped Classroom assessed activities: test and exercise. These activities significantly correlate with the overall final examination score. This result indicates that learners gained understanding the core concepts of Control Valves from semester to semester, a satisfactory trend. In addition, no statistical significance is observed between groups as well as between type-format.

Students are satisfied with the level of suitability and the degree of compliance of the new implementation and found it constructive in their learning process. The quality of materials and homogeneity of guidelines to accomplish the pre-class activities of the Flipped Classroom intervention are positively valued in both groups. The student attendance, achievement, engagement, and reported satisfaction in both groups reinforce the effectiveness of the student-centered approach of the flipped classroom model. A surprise outcome is the low number of students in both cohorts being knowledgeable of the flipped model before the instructors' proposal.

With regard to the SEEQ questionnaire, the results are really positive. All item scores gently grow from the first to the seventh Fall semester. Disappointingly, the explanation of the success or failure of Flipped Classroom approach is disguised by two facts: first, the duration of the intervention and second, the topics on the previous lectures were still taught with traditional methods. This leaves open the question of whether similar results would be achieved across all topics if the entire Turbomachinery section were flipped.

Special attention deserves the Threshold Concepts intervention since a clear achievement could not be properly assessed. Besides, due to the type of data and the deductive nature of reasoning, more attempts are needed to further verify the impact of the Threshold Concepts on academic performance. The instructor learning curve may also be a factor that impacts the effectiveness of the execution. More research is needed, also because the inexperienced instructor has gained knowledge through the implementation. Another aspect that needs further research is the influence of the size of the class. In this case study, the cohorts 
comprised 79 and 88 students. This increase in enrolment was anecdotally, but the number of students per class is quite high when student-centred approaches are willing to be executed. In one hand, the preparation and readiness are more complex, and in the other hand, reaching each learner becomes more limited.

Finally, the Flipped Classroom intervention revealed an excellent ratio benefit-cost. The cost in terms of instructor's time and materials preparation necessary to carry out the intervention was worth and balanced. With regard to students' point of view, both cohorts gave high positive outcomes. The planning scheduling all in-and out-of-class activities of the intervention was the keystone. The authors point out that the results in this case study are only attributable to the student groups in this study and should not be applied if taken out of context.

Future actions will lead to advance in the Flipped Classroom intervention and the Threshold Concepts development.

The positive experience, in terms of benefit-cost and outcomes, encourages to extent the Flipped Classroom intervention to more than one session to cover whole section in the next semesters.

A concept inventory approach in Fluids Engineering in Turbomachinery section will be designed as complementary instrument to threshold concepts development. Future research aims to articulate it as a validated instrument to assess the degree to which students understand the essential knowledge of threshold concepts, from "pre-core" to "post-threshold" concepts.

\section{Acknowledgments}

The authors acknowledge the lecturers and academic staff of the Universitat Politècnica de Catalunya for their teaching and passion for engineering education research. The authors would also like to thank the great aptitude of the students interested in improving the quality of engineering learning and teaching and for answering the survey. Last but not least, the authors want sincerely thank Ms Yoshie Majima for her valuable help answering our questions regarding, among others, to grammar, style, spelling and language editing.

\section{Declaration of Interest statement}

The authors report no potential conflict of interest.

\section{References}

[1] L. Deslauriers, “Physics Class teaching," Science (80-. )., vol. 862, no. May, pp. 862-864, 2011.

[2] S. Freeman et al., "Active learning increases student performance in science, engineering, and mathematics," Proc. Natl. Acad. Sci., vol. 111, no. 23, pp. 8410-8415, 2014.

[3] I. Allen and J. Seaman, "Going the distance: Online Education in the United States," in Electronics Letters, vol. 48, no. 13, M. S. C. Newbury Port, Ed. 2011, p. 742. 
[4] J. Meyer and R. Land, "Threshold Concepts and Troublesome Knowledge," Oxford, Ed. 2003.

[5] J. Martin, J. Mitchell, and T. Newell, "Development of a concept inventory for fluid mechanics," Proc. - Front. Educ. Conf. FIE, vol. 1, p. T3D23-T3D28, 2003.

[6] S. A. Male and D. Bennett, "Threshold concepts in undergraduate engineering: Exploring engineering roles and value of learning," Australas. J. Eng. Educ., vol. 20, no. 1, pp. 59-69, 2015.

[7] J. W. Baker, "The" classroom flip": Using web course management tools to become the guide by the side," Selected Papers From the 11Th International Conference on College Teaching and Learning. pp. 9-17, 2000.

[8] J. Bergmann and A. Sams, Flip your Classroom: Reach Every Student in Every Class Every Day, vol. 3, no. SGEM2016 Conference Proceedings, ISBN 978-619-7105-72-8 / ISSN 2367-5659. 2012.

[9] J. Bishop and M. Verleger, "Testing the flipped classroom with model-eliciting activities and video lectures in a mid-level undergraduate engineering course," Proc. - Front. Educ. Conf. FIE, pp. 161-163, 2013.

[10] J. O'Flaherty and C. Phillips, "The use of flipped classrooms in higher education: A scoping review," Internet High. Educ., vol. 25, pp. 85-95, 2015.

[11] S. J. DeLozier and M. G. Rhodes, "Flipped Classrooms: a Review of Key Ideas and Recommendations for Practice," Educ. Psychol. Rev., vol. 29, no. 1, pp. 141-151, 2017.

[12] M. Marqués Andrés, "Qué hay detrás de la clase al revés (flipped classroom)," ReVisión, vol. 9, no. 3, p. 2, 2016.

[13] G. Akçayır and M. Akçayır, "The flipped classroom: A review of its advantages and challenges," Comput. Educ., vol. 126, no. July, pp. 334-345, 2018.

[14] B. Kerr, "The flipped classroom in engineering education: A survey of the research," Proc. 2015 Int. Conf. Interact. Collab. Learn. ICL 2015, no. September, pp. 815-818, 2015.

[15] L. A. Barba and J. M. Le Doux, "Advances in Engineering Education Guest Editorial: Flipped Classrooms in STEM," pp. 1-6, 2016.

[16] L. Sullivan-Green, P. R. Backer, and A. H. Feinstein, "Analyzing the effects of a flipped classroom pedagogy on freshmen and sophomore STEM courses," Proc. - Front. Educ. Conf. FIE, vol. 2018-Octob, pp. 1-5, 2019.

[17] R. Kay, T. MacDonald, and M. DiGiuseppe, "A comparison of lecture-based, active, and flipped classroom teaching approaches in higher education," J. Comput. High. Educ., vol. 31, no. 3, pp. 449-471, 2019.

[18] P. Bullen and M. Russell, "A blended learning approach to teaching first year engineering degree students," Proc. 6th IASTED Int. Conf. Web-Based Educ. WBE 2007, pp. 470-473, 2007.

[19] L. Albers and L. Bottomley, "The impact of activity based learning, a new instructional method, in an existing mechanical engineering curriculum for fluid mechanics," ASEE Annu. Conf. Expo. Conf. Proc., 2011.

[20] C. J. McClelland, "Flipping a large-enrollment fluid mechanics course - Is it effective?," 
ASEE Annu. Conf. Expo. Conf. Proc., 2013.

[21] P. J. Gamez-Montero, G. Raush, L. Domènech, R. Castilla, M. García-Vílchez, H. Moreno and A. Carbó, "Methodology for Developing Teaching Activities and Materials for Use in Fluid Mechanics Courses in Undergraduate Engineering Programs," Journal of Technology and Science Education, vol. 5, no. 1, pp. 15-30, 2015.

[22] A. Brown, "Engaging students as partners in developing online learning and feedback activities for first-year fluid mechanics," Eur. J. Eng. Educ., vol. 43, no. 1, pp. 26-39, 2018.

[23] D. R. Webster, D. M. Majerich, and A. G. Madden, "Flippin' fluid mechanics Comparison using two groups," Adv. Eng. Educ., vol. 5, no. 3, pp. 1-20, 2016.

[24] H. N. Fedesco and C. Troy, "Why this flip wasn't a flop: What the numbers don't tell you about flipped classes," ASEE Annu. Conf. Expo. Conf. Proc., vol. 2016-June, 2016.

[25] D. J. Harrison, L. Saito, N. Markee, and S. Herzog, "Assessing the effectiveness of a hybrid-flipped model of learning on fluid mechanics instruction: overall course performance, homework, and far- and near-transfer of learning," Eur. J. Eng. Educ., vol. 42, no. 6, pp. 712-728, 2017.

[26] A. Rahman, "A blended learning approach to teach fluid mechanics in engineering," Eur. J. Eng. Educ., vol. 42, no. 3, pp. 252-259, 2017.

[27] F. L. Wachs et al., "Successfully flipping a fluid mechanics course using video tutorials and active learning strategies: Implementation and assessment," ASEE Annu. Conf. Expo. Conf. Proc., vol. 2018-June, 2018.

[28] B. A. W. Chickering and Z. F. Gamson, "Seven Principles for Good Practice in Undergraduate Education Seven Principles of Good Practice," AAHE Bull., no. March, p. 7, 1987.

[29] D. A. Green, J. Loertscher, V. Minderhout, and J. E. Lewis, "For want of a better word: unlocking threshold concepts in natural sciences with a key from the humanities?," High. Educ. Res. Dev., vol. 36, no. 7, pp. 1401-1417, 2017.

[30] D. Reeping et al., "How are threshold concepts applied? A review of the literature," ASEE Annu. Conf. Expo. Conf. Proc., vol. 2017-June, 2017.

[31] A. Churches, "Bloom's Taxonomy blooms digitally," Tech Learn., vol. 196605124, pp. 16, 2008 .

[32] J. L. Jensen, E. A. Holt, J. B. Sowards, T. Heath Ogden, and R. E. West, "Investigating Strategies for Pre-Class Content Learning in a Flipped Classroom," J. Sci. Educ. Technol., vol. 27, no. 6, pp. 523-535, 2018.

[33] M. Coffey and G. Gibbs, "The evaluation of the student evaluation of educational quality questionnaire (SEEQ) in UK higher education," Assess. Eval. High. Educ., vol. 26, no. 1, pp. 89-93, 2001.

How to cite this article: Gamez-Montero PJ, Peña M, Olmedo-Torre N. Flipped learning and threshold concepts in the Turbomachinery section of Fluid Engineering course. Comput Appl Eng Educ. 2020;1-15. https://doi.org/10.1002/cae.22280 